\title{
Dropping risk stratification with subsequent treatment-risk paradox in non ST elevation acute coronary syndromes: a clinical audit in Iraq
}

Zainab Atiyah Dakhil ${ }^{1 *}$ and Hasan Ali Farhan ${ }^{2,3}$

\begin{abstract}
Background: Risk stratification is the cornerstone in managing patients with Non-ST Elevation Acute Coronary Syndromes (NSTE-ACS) and can attenuate the unjustified variability in treatment and guide the intervention decision notwithstanding its impact on better healthcare resources use. This study sought to disclose real adherence to guidelines in risk stratification of NSTE-ACS patients and in adopting intervention decision in practice.

Methods: Multicentre prospective study recruited NSTE-ACS patients. Baseline characteristics were collected, TIMI (Thrombolysis in Myocardial Infarction) and GRACE (Global Registry of Acute Coronary Events) scores were calculated, management strategy as well as timing to intervention were recorded.

Results: $n .=150,72 \%$ of them were males, mean age was (59 \pm 12.32 ) years. TIMI score was calculated in $5.3 \%$ of patients with none of them had GRACE score calculated. Invasive strategy was adopted in 85.24 and $82.7 \%$ of low GRACE and TIMI risk categories respectively, while invasive approach used in 42.85 and $40 \%$ of high GRACE and TIMI risk categories respectively. The immediate intervention in less than 2 hours was more to be used in low-risk categories while the high-risk and very high-risk patients whom were managed invasively were catheterized within $>72 \mathrm{~h}$; or more frequently to be non-catheterized at all. Sixty percent of those with acute heart failure, $80.76 \%$ of those with ongoing chest pain, $85 \%$ of those with dynamic ST changes same as $80 \%$ of those with cardiogenic shock were treated conservatively. Using multivariable analysis older age, ongoing chest pain and cardiogenic shock predicted conservative approach.
\end{abstract}

\footnotetext{
* Correspondence: stethoscope.med@gmail.com

'Department of Medicine, Al Kindy College of Medicine, University of Baghdad, Baghdad, Iraq

Full list of author information is available at the end of the article
}

(c) The Author(s). 2021 Open Access This article is licensed under a Creative Commons Attribution 4.0 International License, which permits use, sharing, adaptation, distribution and reproduction in any medium or format, as long as you give appropriate credit to the original author(s) and the source, provide a link to the Creative Commons licence, and indicate if changes were made. The images or other third party material in this article are included in the article's Creative Commons licence, unless indicated otherwise in a credit line to the material. If material is not included in the article's Creative Commons licence and your intended use is not permitted by statutory regulation or exceeds the permitted use, you will need to obtain permission directly from the copyright holder. To view a copy of this licence, visit http://creativecommons.org/licenses/by/4.0/ The Creative Commons Public Domain Dedication waiver (http://creativecommons.org/publicdomain/zero/1.0/) applies to the data made available in this article, unless otherwise stated in a credit line to the data. 
Conclusions: There is striking underuse of risk scores in practice that can contribute to treatment-risk paradox in managing NSTE-ACS in form of depriving those with higher risk from invasive strategy despite being the most beneficiaries. The paradox did not only involve the very high-risk patients but also the very high-risk criteria like ongoing chest pain and cardiogenic shock predicted conservative approach, this highlights that the entire approach to patients with NSTE-ACS should be reconsidered, regardless of the use of risk scores in clinical practice. Audit programs activation in middle eastern countries can inform policymakers to put a limit to the treatment-risk paradox for better cardiovascular care and outcomes.

Keywords: Audit, Guideline adherence, Healthcare policy, Middle East, Risk scores

\section{Introduction}

According to WHO survey (2017) death from coronary artery disease $(\mathrm{CAD})$ in Iraq reached about $18.5 \%$ of total deaths [1]. This big killer; CAD; mainly presented as either chronic stable angina or acute coronary syndrome (ACS). Despite Non ST elevation myocardial infarction (NSTE $\mathrm{MI}$ ) incidence continues to rise with greater improvement in outcomes of ACS patients in last decades, long term outcomes have not improved in NSTEMI at the same rate of ST elevation myocardial infarction (STEMI) a suggested explanation is depriving those with most benefit from intervention [2]. This necessitates using objective risk stratification tools to guide management plan in NSTEACS with TIMI and GRACE scores being most reliable tools, proper risk assessment of NSTE-ACS patients is mandatory to guide the triage among alternative levels of hospital care (e.g., Coronary Care Unit [CCU] vs hospital ward vs outpatient care) [2, 3], as well as decision and timing of intervention [3-6] as following:

"Very high-risk criteria patients (Shock, acute heart failure, ongoing chest pain, life threatening arrhythmia, mechanical complications, or recurrent dynamic Electrocardiogram [ECG] changes) should be catheterised within 2 hours.

"High risk patients (NSTEMI, dynamic ECG changes, GRACE score more than 140) should be catheterised within $24 \mathrm{~h}$.

"Intermediate risk category (diabetes, renal insufficiency, or left ventricular ejection fraction less than 40 , post $\mathrm{MI}$ angina or prior CABG or GRACE score 109-140) should be catheterised within $72 \mathrm{~h}$.

It is noted that patients who can benefit mostly from treatment are not being treated because there is an exaggerated fear from treatment complications. This phenomenon, often referred to as the 'treatment-risk paradox' $[7,8]$. Underuse of risk scores may explain this paradox, as health professionals disagree on the importance of cardiac risk scores used to decide on the management of NSTE-ACS patients $[9,10]$.

This study sought to investigate the adherence of cardiologists to international guidelines in managing NSTE-ACS patients in form of using risk stratification scores (TIMI and GRACE scores) in daily practice in Iraq and to determine if there is treatment-risk paradox in catheterising this population and the predictors of this paradox if present.

\section{Patients and methods \\ Design}

Multicentre and prospective study, it is part of clinical audit that was conducted to evaluate all aspects of management of patients with NSTE-ACS.

\section{Setting and duration}

The study conducted in Iraq and included three cardiac centres, that are teaching centres and percutaneous coronary intervention (PCI) capable centres with 24/7-day emergency PCI services. The study started from January 2018 to January 2019. Cases recruitment done sequentially (not simultaneously) during affiliation period of the investigator in each of these three cardiac centres.

\section{Patient selection}

The study included patients with confirmed diagnosis of NSTE-ACS (Patients with acute chest pain but no persistent ST-segment elevation) [6], the diagnosis of NSTE-ACS was confirmed by the head of the treating team who was usually a consultant cardiologist.

\section{Exclusion Criteria}

1. Persistent ST elevation on ECG 2. New or presumed new left bundle branch block (LBBB) 3. Active malignancy 4. End stage renal disease 5. Active Upper GIT bleeding 6. Patients refusing intervention 7. Frail patient 8. Any patient with missed data (regarding in-hospital follow ups and checking for development of the highrisk features, time to catheterization lab) was excluded from the study.

Role of investigator in cases selection and data collection The investigator registered the case, TIMI and GRACE risk scores were calculated by the investigator, then the investigator attended the daily morning rounds and follow-up meetings with the treating team and evaluated the management plans and determined whether or not 
the treating team calculated the risk scores during any step in management. So, researchers did not only depend on patients' records, to overcome the limitation that was reported by prior researchers [4] in that checking only risk scores from patients' records would not reflect the real-world practice thus even verbal score calculation during daily rounds would be considered as positively calculated score in current study.

\section{Primary outcomes}

Primary outcome measures of this study were calculation or not of risk scores in practice and decision of intervention in NSTE-ACS according to risk category.

\section{Ethical approval}

This study was part of conducted clinical audit regarding management of NSTE-ACS. It was performed in accordance with the declaration of Helsinki and approved by ethical and scientific committees in Iraqi Scientific Council of Cardiology/ Iraqi Board for Medical Specializations. Informed consent to be enrolled in the study was obtained from all patients.

\section{Statistical analysis}

Collected data were coded and input into computer using IBM SPSS Statistics version 24. Numerical variables are expressed as mean \pm standard deviation, categorical variables were expressed as percentages. Statistical analysis of numerical variables was done by $\mathrm{t}$ test, while that of categorical variables were done by Chi-Square test to compare frequency ratios between categories. Multiple logistic regression was used to assess predictors of invasive strategy in study population. $P$ value $<0.05$ is considered statistically significant [11].

\section{Results}

One hundred fifty patients with NSTE-ACS were included in this study,108 (72\%) of them were males with male to female ratio of (2.57:1). Age of patients ranges from 25 to 85 years with a mean age $(59 \pm 12.32)$ years. Tables 1 and 2 demonstrates main demographic features of patients according to GRACE and TIMI risk categories, there is the clear underuse of risk scores as TIMI score was only calculated in 8 patients (5.3\%).

Our results cast a light on timing to catheterization for whom managed invasively in all GRACE, TIMI risk categories and in very high-risk category as illustrated in Figs. 1 and 2. The immediate intervention in less than 2 hours was more to be used in low risk categories while the high-risk and very high-risk patients who were managed invasively were catheterized within $>72 \mathrm{~h}$ or more frequently to be non-catheterized at all. Multiple logistic regression model was used to evaluate the impact of these independent variables on decision making as shown in Table 3. There was no significant difference in in-hospital outcomes according to management strategy as seen in Fig. 3.

\section{Discussion}

Current study highlighted the limited use of risk scores in our daily practice in stratifying NSTE-ACS patients and illuminated the Treatment-Risk Paradox phenomenon that was remarkable in managing this patient population. This was the first designed clinical audit in cardiology field in Iraq. To date, in Iraq limited data is known about the extent of adherence of NSTEACS treating cardiac teams to the global guidelines regarding recommendations on risk stratification and subsequent performance of cardiac catheterization based on patients' risk and within the recommended time frames for each risk category [12]. Moreover, this is the first study that actively and prospectively assessed use of risk scores adherence (i.e., not like prior studies that assessed use of risk scores from patients' charts after discharge) for patients who were diagnosed as NSTE-ACS. Thus, current study can inform the policymakers to optimize use of hospital resources by the appropriate use of intervention in the right time for the right patient, many prior researchers in other countries made influential changes in practice and improved patients' outcomes by similar studies [13-15].

The study highlights huge practice gap in form of underuse of risk scores in practice as without proper risk stratification, patient's treatment path will certainly be misdirected, from international guidelines [5, 6, 16-18] we can conclude that risk stratification is not a (better to be done) recommendation, it is a (must be done) one. So, dropping this step will certainly lead to treatmentrisk paradox.

High GRACE and TIMI risk categories as well as those with very high-risk criteria were more to be treated conservatively and even when treated invasively there was a delay in timing to catheterization compared to lower risk patients, comparative studies reported more catheterization in those with cardiogenic shock, recurrent ischemia or heart failure, and those who were managed by cardiologists rather than internists however, all our recruited patients were managed by cardiologists and cardiology fellows. Treatment-risk paradox can partly be explained by clinicians' reluctance to perform invasive procedures in patients perceived to be at high risk for developing procedure related complications, e.g., bleeding, contrast induced kidney injury, stroke [19-21]. Our findings of such treatment-risk paradox involving even those with very-high risk criteria highlight that the entire approach to patients with clinical suspicion of NSTE-ACS should be reconsidered, regardless of the use of risk scores in clinical practice. 
Table 1 Distribution of Initial Demographic Data According to GRACE Risk Class

\begin{tabular}{|c|c|c|c|c|}
\hline \multirow[t]{2}{*}{ Variable } & \multicolumn{3}{|c|}{ GRACE Score Category } & \multirow[t]{2}{*}{$P$ Value } \\
\hline & Low & Intermediate & High & \\
\hline Age $($ Mean \pm SD) & $51.84 \pm 9.97$ & $60.65 \pm 11.19$ & $66.57 \pm 10.94$ & $<0.0001$ \\
\hline Male Gender n.(\%) & $45(41.7 \%)$ & $29(26.85 \%)$ & $34(31.5 \%)$ & 0.876 \\
\hline Female Gender n.(\%) & $16(38 \%)$ & $11(26.2 \%)$ & 15 (35.71\%) & \\
\hline Hypertension n.(\%) & $40(37.4 \%)$ & $30(28.03 \%)$ & $37(34.6 \%)$ & 0.434 \\
\hline Diabetes Mellitus n.(\%) & $25(33.3 \%)$ & $19(25.3 \%)$ & $31(41.3 \%)$ & 0.063 \\
\hline Ischemic Heart Disease n.(\%) & $23(30.7 \%)$ & $19(25.3 \%)$ & $33(44 \%)$ & 0.008 \\
\hline Smoking n.(\%) & $27(55.1 \%)$ & $11(22.44 \%)$ & $11(22.44 \%)$ & 0.038 \\
\hline Stroke n.(\%) & $1(50 \%)$ & $1(50 \%)$ & 0 & 0.571 \\
\hline Dyslipidemia n.(\%) & $12(33.3 \%)$ & $10(27.8 \%)$ & $14(38.9 \%)$ & 0.546 \\
\hline Family History n.(\%) & $30(49.18 \%)$ & $11(18.03 \%)$ & $20(32.8 \%)$ & 0.095 \\
\hline Prior Catheterization n.(\%) & $5(29.41 \%)$ & $3(17.64 \%)$ & $6(35.3 \%)$ & 0.690 \\
\hline Prior PCI n.(\%) & $12(46.15 \%)$ & $3(11.53 \%)$ & $11(42.3 \%)$ & 0.148 \\
\hline Prior CABG n.(\%) & 0 & $1(33.3 \%)$ & $2(66.7 \%)$ & 0.304 \\
\hline Chest Pain n.(\%) & $56(39.2 \%)$ & $38(26.6 \%)$ & $49(34.3 \%)$ & 0.19 \\
\hline Dyspnea n.(\%) & $7(15.9 \%)$ & $11(25 \%)$ & $26(59.09 \%)$ & $<0.0001$ \\
\hline Pulse Rate (Mean \pm SD) beat per minute & $76.21 \pm 14.26$ & $84.53 \pm 21.41$ & $96.67 \pm 23.64$ & $<0.0001$ \\
\hline Baseline Systolic Blood Pressure (Mean \pm SD) mmHg & $138.59 \pm 23.36$ & $138.83 \pm 30.56$ & $132.14 \pm 25.1$ & 0.355 \\
\hline Baseline Diastolic Blood Pressure (Mean \pm SD) mmHg & $83.93 \pm 12.27$ & $82.7 \pm 13.5$ & $78.06 \pm 12.36$ & 0.048 \\
\hline Positive Troponin (\%) & $17(24.6 \%)$ & $17(24.6 \%)$ & $35(50.7 \%)$ & $<0.0001$ \\
\hline GRACE Risk Score Calculation by The Treating Team (\%) & 0 & 0 & 0 & N/A \\
\hline
\end{tabular}

Table 2 Distribution of Initial Demographic Data According to TIMI Risk Class

\begin{tabular}{|c|c|c|c|c|}
\hline \multirow[t]{2}{*}{ Variable } & \multicolumn{3}{|c|}{ TIMI Score Category } & \multirow[t]{2}{*}{$P$ Value } \\
\hline & Low & Intermediate & High & \\
\hline Age (Mean $\pm S D)$ & $53.65 \pm 12.19$ & $60.15 \pm 11.34$ & $66.76 \pm 10.63$ & $<0.0001$ \\
\hline Male Gender n.(\%) & 39 (36.11\%) & $52(48.14 \%)$ & $17(15.74 \%)$ & 0.798 \\
\hline Female Gender n.(\%) & $13(30.95 \%)$ & $21(50 \%)$ & $8(19.04 \%)$ & \\
\hline Hypertension n.(\%) & $30(28.03 \%)$ & $57(53.27 \%)$ & $20(18.69 \%)$ & 0.026 \\
\hline Diabetes Mellitus n.(\%) & $15(20 \%)$ & $43(57.33 \%)$ & $17(22.66 \%)$ & 0.001 \\
\hline Ischemic Heart Disease n.(\%) & $18(24 \%)$ & $36(48 \%)$ & $21(28 \%)$ & 0.001 \\
\hline Smoking n.(\%) & 20 (40.81\%) & $23(46.93 \%)$ & $6(12.24 \%)$ & 0.429 \\
\hline Stroke n.(\%) & $1(50 \%)$ & $1(50 \%)$ & 0 & 0.148 \\
\hline Dyslipidemia n.(\%) & $5(13.88 \%)$ & $20(55.55 \%)$ & $11(30.55 \%)$ & 0.003 \\
\hline Family History n.(\%) & $13(21.31 \%)$ & 35 (57.37\%) & $13(21.31 \%)$ & 0.016 \\
\hline Prior Catheterization n.(\%) & $3(17.64 \%)$ & $8(47.05 \%)$ & $6(35.29 \%)$ & 0.25 \\
\hline PCI n.(\%) & $6(23.07 \%)$ & $12(46.15 \%)$ & $8(30.76 \%)$ & 0.082 \\
\hline CABG n.(\%) & 0 & $1(33.3 \%)$ & $2(66.7 \%)$ & 0.055 \\
\hline Chest Pain n.(\%) & $36(26.86 \%)$ & $71(52.98 \%)$ & $36(26.86 \%)$ & 0.075 \\
\hline Dyspnea n.(\%) & $8(18.18 \%)$ & $25(56.81 \%)$ & $11(25 \%)$ & 0.016 \\
\hline Pulse Rate (Mean $\pm S D$ ) beat per minute & $79.56 \pm 15.73$ & $86.97 \pm 24.92$ & $91.24 \pm 18.46$ & 0.046 \\
\hline Baseline Systolic Blood Pressure (Mean \pm SD) mmHg & $130.08 \pm 23$ & $140.81 \pm 26.69$ & $137.56 \pm 26.16$ & 0.073 \\
\hline Baseline Diastolic Blood Pressure (Mean \pm SD) $\mathrm{mmHg}$ & $79.88 \pm 12.65$ & $82.52 \pm 13.04$ & $83 \pm 12.58$ & 0.452 \\
\hline Positive Troponin (\%) & $10(14.5 \%)$ & $39(56.5 \%)$ & $20(29 \%)$ & $<0.0001$ \\
\hline TIMI Risk Score Calculation by The Treating Team (\%) & $1(20 \%)$ & $2(40 \%)$ & $2(40 \%)$ & 0.352 \\
\hline
\end{tabular}




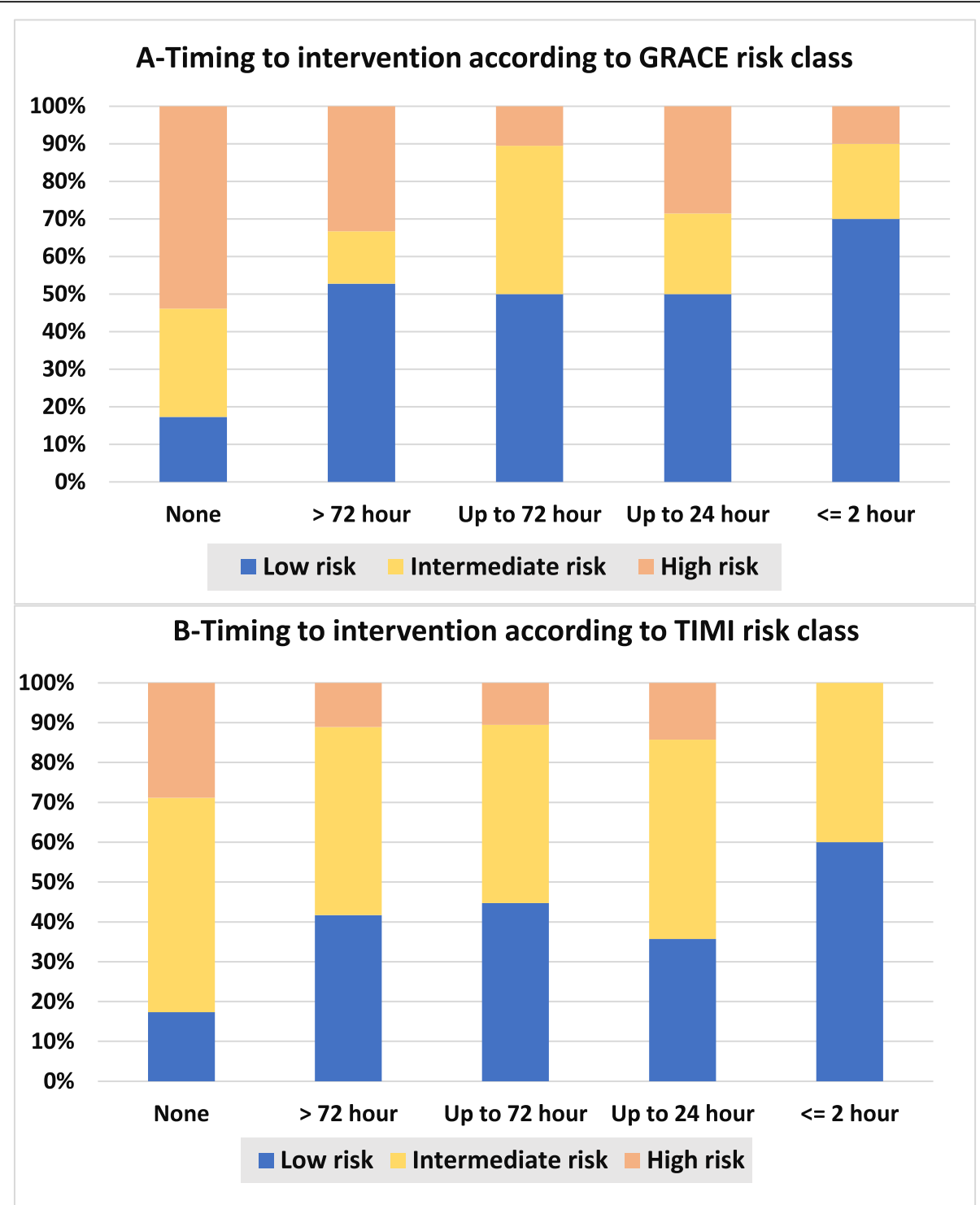

Fig. 1 Timing to Intervention in Patients with NSTE-ACS According to GRACE and TIMI Risk Classes§. §Comparing conservative strategy versus invasive strategy according to GRACE risk class $p<0.0001$. Comparing timing to catheterization according to GRACE risk class $p=0.037$. Comparing conservative strategy versus invasive strategy according to TIMI risk class $p=0.873$. Comparing timing to catheterization according to TIMI risk class $p=0.001$

In a middle eastern country like Iraq, there is a vital social aspect that cannot be overlooked in real practice which is the premonition of the (Clannish Mores And Customs) and (Tribal Wergild), such premonitions push the physicians (especially interventionists) towards more conservative approach in high and very high risk patients despite the benefit from invasive strategy, since any complication or poor prognostic outcome even if scientifically justified considered unacceptable and definitely unforgivable by patients' tribe and can cost the physician his life especially in absence of powerful system backup and law authority [22] as over the last 15 years, 20,000 doctors left Iraq seeking job abroad fearing from tribal vendettas, while $70 \%$ of Iraqi health personnel are considering leaving Iraq due to tribal customs and chaotic law authority [23]. Such socio-cultural aspects can explain not only treatment-risk paradox in current practice by impacting physicians' decision-making but also the disparity in the rate of adherence to guidelines in form of lower adherence in these countries when compared to developed counterparts. Shedding a light on treatment decision in view of these factors with subsequent 


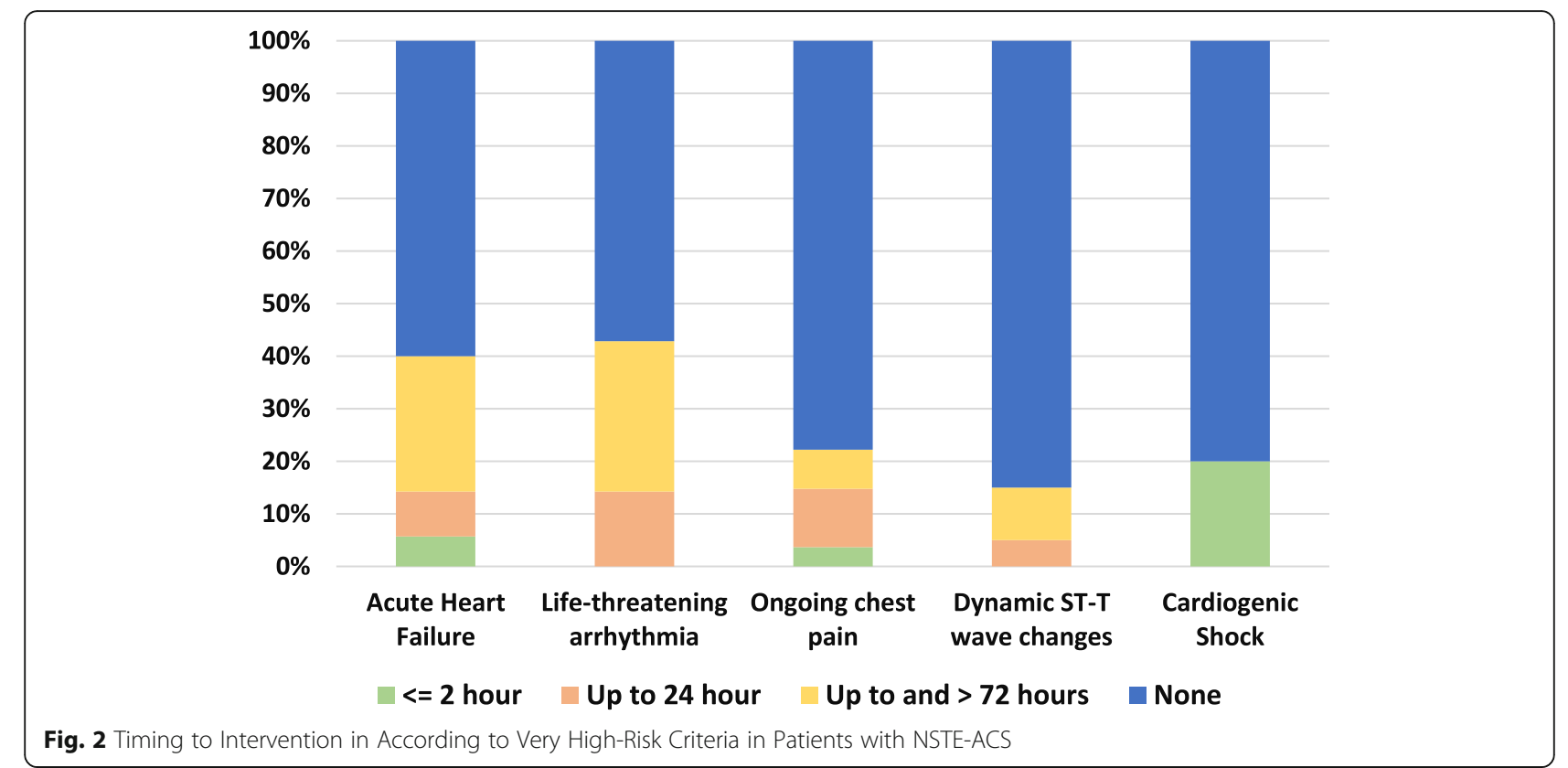

disparity can alert the policymakers to their vital role in establishing a supportive healthcare system that can help in enhancing the decision making of physicians and increasing their adherence to guidelines, there is a successful experience in this regard in Iraq [22].

Adherence to guidelines in term of decision and timing of intervention in NSTE-ACS play a key role in improving patients' outcomes, as the highest benefit was reported in high risk patients who were treated invasively in form of absolute risk reduction in addition to decrease recurrent ischemia, subsequent rehospitalization and revascularization as well as cardiovascular death and all-cause mortality at 30-days, 12 months and 5-years follow-up [15, 24]. Recent Meta-analysis [25] provides strong evidence regarding the highest benefit of early invasive strategy in higher risk NSTE-ACS in term of lower major adverse cardiac events and recurrent ischemic events in parallel to what was reported by VERDICT trial [26]. However, we did not observe significant differences in in-hospital outcomes according to use of invasive strategy and this can be explained by the delayed

Table 3 Multiple Logistic Regression Analysis of Variables Predicting Invasive Strategy

\begin{tabular}{|c|c|c|c|c|c|}
\hline \multirow[t]{2}{*}{ Variable } & \multirow{2}{*}{$\begin{array}{l}\text { Standardized } \\
\text { Coefficient } \\
\text { Beta }\end{array}$} & \multirow{2}{*}{$\begin{array}{l}\text { Standard } \\
\text { Error (SE) }\end{array}$} & \multicolumn{2}{|l|}{$95 \% \mathrm{Cl}$} & \multirow[t]{2}{*}{$P$ Value } \\
\hline & & & Lower Limit & Upper Limit & \\
\hline Age & -0.189 & 0.003 & -0.014 & -0.001 & 0.033 \\
\hline Female Gender & -0.091 & 0.082 & -0.259 & 0.066 & 0.242 \\
\hline GRACE Score > 140 & -0.111 & 0.104 & -0.318 & 0.093 & 0.280 \\
\hline Diabetes Mellitus & -0.089 & 0.079 & -0.240 & 0.071 & 0.285 \\
\hline Prior Catheterisation & 0.000 & 0.132 & -0.260 & 0.261 & 0.998 \\
\hline Prior $\mathrm{PCl}$ & -0.026 & 0.099 & -0.230 & 0.164 & 0.740 \\
\hline Atrial Fibrillation/Flutter & -0.100 & 0.148 & -0.477 & 0.111 & 0.22 \\
\hline Positve Troponin & 0.148 & 0.079 & -0.015 & 0.297 & 0.075 \\
\hline Acute Heart Failure & -0.142 & 0.101 & -0.359 & 0.039 & 0.115 \\
\hline Ongoing Chest Pain & -0.210 & 0.106 & -0.473 & -0.055 & 0.014 \\
\hline Cardiogenic Shock & -0.162 & 0.207 & -0.837 & -0.019 & 0.04 \\
\hline Life-Threatening Arrhythmias & 0.048 & 0.164 & -0.224 & 0.425 & 0.541 \\
\hline Risk Score Calculation by The Treating Team & 0.041 & 0.211 & -0.308 & 0.527 & 0.605 \\
\hline
\end{tabular}




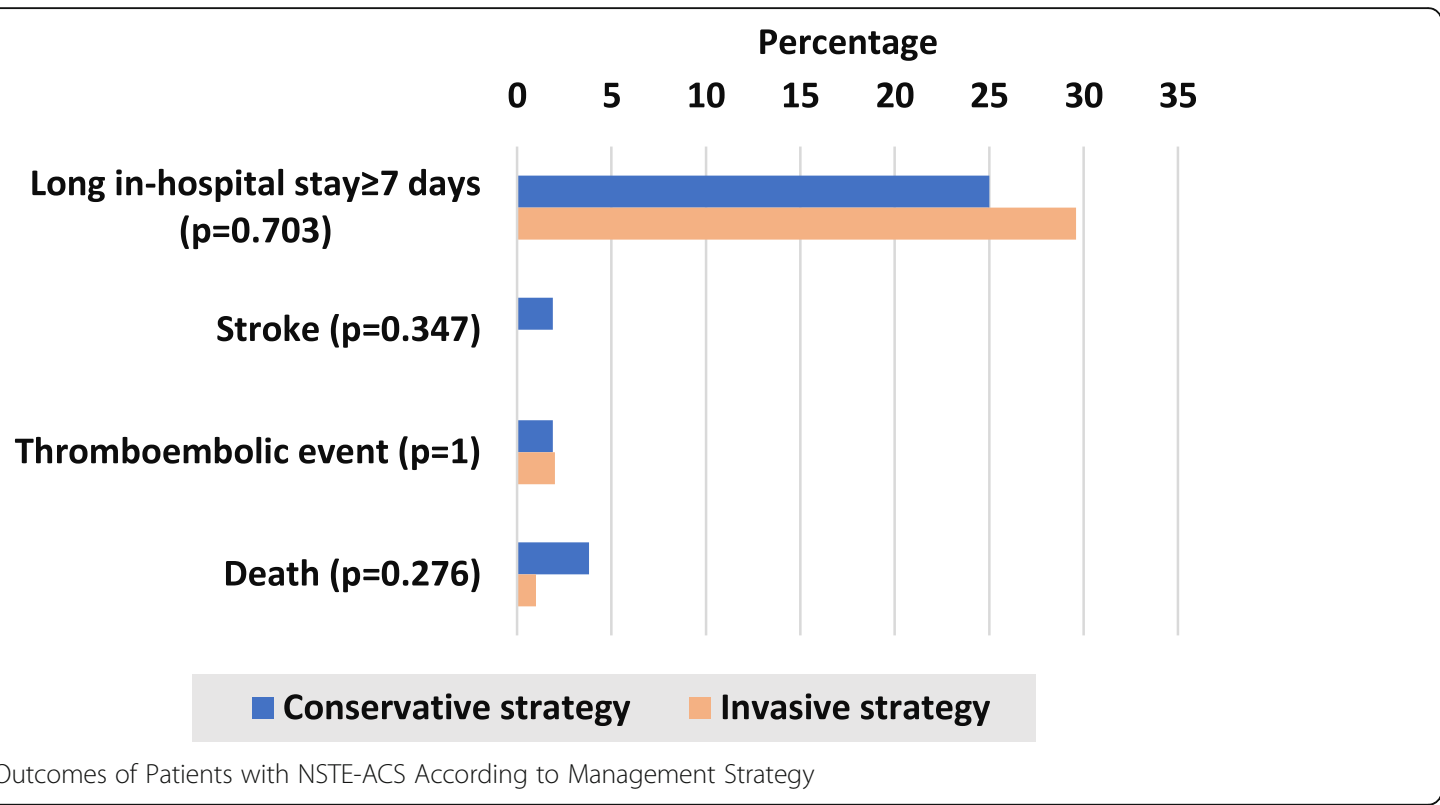

catheterization if done in high-risk patients which can partially waive its benefit or catheterizing low riskpatients who usually benefit less from intervention compared to the higher risk categories.

Not only for improving patients' outcomes but being an emerging country with limited resources, absent health insurance policy and absent nongovernmental funding with a few numbers of cardiac centres, in addition to shortage of staff and above all; shortage of materials and supplies for intervention, sometimes with total absence for remarkable periods. All that necessitate that our resources and efforts should be targeted towards the higher risk class to optimize patients' outcomes.

To overcome treatment-risk paradox in practice we recommend specifying a highlighted box for documenting the risk of patients in hospital records once admitted to CCU to motivate the residents to consider risk stratification in practice. We suggest using teaching posters and pocket guides to promote adherence to guidelines. We recommend that mentors and trainers emphasize more on proper risk stratification and adherence to evidence-based management during grand rounds and meetings. In high volume centres, we propose prioritizing the higher risk patients and emergency procedures over elective ones in resourcelimited settings. Moreover, it is crucial to conduct clinical audits with further communication with decision-makers to ensure proper feedback to conduct quality improvement projects to optimize patients' outcomes and achieve cost-effectiveness of performed measures and procedures.

\section{Study limitations}

Larger sample size is warranted in future to further validate the results, the strict selection of cases especially regarding the mandatory presence of the investigator during daily follow-up limited substantially the sample size in addition to absent electronic database and lack of research collaborators. Long-term prognostic outcomes resulting from the treatment-risk paradox can add more insights to the impact of this practice gap to catch the attention of healthcare providers to the importance of adherence to guidelines in daily practice.

\section{Conclusions}

There is striking underuse of risk scores in practice that can contribute to treatment-risk paradox in managing NSTE-ACS in form of depriving those with higher risk from invasive strategy despite being the most beneficiaries. The paradox did not only involve the very high-risk patients but also the very high-risk criteria like ongoing chest pain and cardiogenic shock predicted conservative approach, this highlights that the entire approach to patients with NSTE-ACS should be reconsidered, regardless of the use of risk scores in clinical practice. Audit programs activation in middle eastern countries can inform policymakers to put a limit to the treatment-risk paradox for better cardiovascular care and outcomes.

\section{Abbreviations}

ACS: Acute Coronary Syndrome; CABG: Coronary Artery Bypass Graft; CAD: Coronary Artery Disease; CCU: Coronary Care Unit;

ECG: Electrocardiogram; GRACE: Global Registry of Acute Coronary Events; LBBB: Left Bundle Branch Block; NSTE-ACS: Non-ST Elevation Acute Coronary Syndromes; NSTEMI: Non ST Elevation Myocardial Infarction; 
PCI: Percutaneous Coronary Intervention; STEMI: ST Elevation Myocardial Infarction; TIMl: Thrombolysis in Myocardial Infarction

\section{Acknowledgements}

The authors thank the medical staff at Ibn Al-Bitar Cardiac Centre, Baghdad Heart Centre and Nasiriyah Heart Centre for helping the investigators during data collection process.

\section{Authors' contributions}

ZAD and HAF contributed to the concept of the study, revising and approving the final version. ZAD was responsible for study design, data collection, statistical analysis, data interpretation and drafting first manuscript.

\section{Funding}

Not applicable.

\section{Availability of data and materials}

The data sets used and/or analysed during the study are available from the corresponding author on reasonable request.

\section{Declarations}

\section{Ethics approval and consent to participate}

The authors assert that all procedures contributing to this work comply with the ethical standards of the relevant national Iraqi guidelines and with the Helsinki Declaration of 1975, as revised in 2008, this study is part of a clinical audit on management of NSTE-ACS that has been approved by the ethical and scientific committee in Scientific Council of Cardiology/ Iraqi Board for Medical Specializations. Written informed consent was obtained from all the participants.

\section{Consent for publication}

Not applicable.

\section{Competing interests}

Not applicable.

\section{Author details}

${ }^{1}$ Department of Medicine, Al Kindy College of Medicine, University of Baghdad, Baghdad, Iraq. Iraqi Scentific Council of Cardiology/ Iraqi Board for Medical Specializations, Baghdad, Iraq. ${ }^{3}$ Baghdad Heart Centre/ Medical City, Baghdad, Iraq.

Received: 4 November 2020 Accepted: 15 September 2021 Published online: 26 September 2021

\section{References}

1. Iraq coronary heart disease [Internet]. Data source: WHO 2017. Cited last February 2019. Available from https://www.worldlifeexpectancy.com/iraqcoronary-heart-disease.

2. Cohen M. Long-term outcomes in high-risk patients with non-ST-segment elevation myocardial infarction. J Thromb Thrombolysis. 2016;41(3):464-74 https://doi.org/10.1007/s11239-015-1227-1.

3. Yan AT, Yan RT, Huynh T, Casanova A, Raimondo FE, Fitchett DH, et al. Understanding physicians' risk stratification of acute coronary syndromes: insights from the Canadian ACS 2 registry. Arch Intern Med. 2009;169(4): 372-8. https://doi.org/10.1001/archinternmed.2008.563.

4. Engel J, van der Wulp I, de Bruijne M, Wagner C. A cross-sectional multicentre study of cardiac risk score use in the management of unstable angina and non-ST-elevation myocardial infarction. BMJ Open. 2015;5(11): e008523. https://doi.org/10.1136/bmjopen-2015-008523.

5. Neumann FJ, Sousa-Uva M, Ahlsson A, Alfonso F, Banning AP, Benedetto U, et al. 2018 ESC/EACTS guidelines on myocardial revascularization. Eur Heart J. 2018;40(2):87-165.

6. Damman P, van't Hof AW, Ten Berg JM, Jukema JW, Appelman Y, Liem AH, et al. 2015 ESC guidelines for the management of acute coronary syndromes in patients presenting without persistent ST-segment elevation: comments from the Dutch ACS working group. Neth Hear J. 2017;25(3): 181-5. https://doi.org/10.1007/s12471-016-0939-y.
7. Knudtson ML, Norris CM, Galbraith PD, Hubacek J, Ghali WA. Explicit risk in acute coronary syndrome management. Can J Cardiol. 2009:25:29A-36A. https://doi.org/10.1016/S0828-282X(09)71051-7.

8. Resnic FS, Welt FG. The public health hazards of risk avoidance associated with public reporting of risk-adjusted outcomes in coronary intervention. Am Coll Cardiol. 2009;53(10):825-30. https://doi.org/10.1016/j.jacc.2008.11. 034.

9. Engel J, Heeren MJ, van der Wulp I, de Bruijne MC, Wagner C Understanding factors that influence the use of risk scoring instruments in the management of patients with unstable angina or non-ST-elevation myocardial infarction in the Netherlands: a qualitative study of health care practitioners' perceptions. BMC Health Serv Res. 2014;14(1):418. https://doi. org/10.1186/1472-6963-14-418.

10. McAlister FA, Oreopoulos A, Norris CM, Graham MM, Tsuyuki RT, Knudtson $M$, et al. Exploring the treatment-risk paradox in coronary disease. Arch Intern Med. 2007;167(10):1019-25. https://doi.org/10.1001/archinte.167.10.1 019.

11. Shuster JJ. CRC handbook of sample size guidelines for clinical trials: CRC Press; 2019. p. 1-862.

12. Dakhil ZA, Farhan HA. Non-ST elevation acute coronary syndromes; clinical landscape, management strategy and in-hospital outcomes: an age perspective. Egypt Heart J. 2021;73(1):33. https://doi.org/10.1186/s43044021-00155-8.

13. Peterson ED, Roe MT, Mulgund J, DeLong ER, Lytle BL, Brindis RG, et al. Association between hospital process performance and outcomes among patients with acute coronary syndromes. Jama. 2006;295(16):1912-20. https://doi.org/10.1001/jama.295.16.1912.

14. Yan AT, Yan RT, Tan M, Huynh T, Soghrati K, Brunner L, et al. Registries investigators. Optimal medical therapy at discharge in patients with acute coronary syndromes: temporal changes, characteristics, and 1-year outcome. Am Heart J. 2007;154(6):1108-15. https://doi.org/10.1016/j.ahj.2007.07.040.

15. Badings EA, Hermanides RS, Van Der Sluis A, Dambrink JH, Gosselink AT, Kedhi $E$, et al. Use, timing and outcome of coronary angiography in patients with high-risk non-ST-segment elevation acute coronary syndrome in daily clinical practice: insights from a 'real world'prospective registry. Netherlands Heart Journal. 2019;27(2):73-80. https://doi.org/10.1007/s12471-018-1212-3.

16. de Araújo GP, Ferreira J, Aguiar C, Seabra-Gomes R. TIMI, PURSUIT, and GRACE risk scores: sustained prognostic value and interaction with revascularization in NSTE-ACS. Eur Heart J. 2005;26(9):865-72. https://doi. org/10.1093/eurheartj/ehi187.

17. Amsterdam EA, Wenger NK, Brindis RG, Casey DE, Ganiats TG, Holmes DR, et al. 2014 AHA/ACC guideline for the management of patients with nonST-elevation acute coronary syndromes: a report of the American College of Cardiology/American Heart Association task force on practice guidelines. J Am Coll Cardiol. 2014;64(24):e139-228. https://doi.org/10.1016/j.jacc.2014.09. 017.

18. Roffi M, Patrono C, Collet JP, Mueller C, Valgimigli M, Andreotti F, et al. 2015 ESC guidelines for the management of acute coronary syndromes in patients presenting without persistent STsegment elevation: task force for the Management of Acute Coronary Syndromes in patients presenting without persistent ST-segment elevation of the European Society of Cardiology (ESC). Eur Heart J. 2016;37(3):267-315. https://doi.org/10.1093/ eurheartj/ehv320.

19. Saar A, Marandi T, Ainla T, Fischer K, Blöndal M, Eha J. The risk-treatment paradox in non-ST-elevation myocardial infarction patients according to their estimated GRACE risk. Int J Cardiol. 2018;272:26-32. https://doi.org/10.1 016/j.jijcard.2018.08.015.

20. Panduranga P, Sulaiman K, Al-Zakwani I, Zubaid M, Rashed W, Al-Mahmeed W, et al. Utilization and determinants of in-hospital cardiac catheterization in patients with acute coronary syndrome from the Middle East. Angiology. 2010;61(8):744-50. https://doi.org/10.1177/0003319710369794.

21. Henderson RA. Acute coronary syndrome: optimising management through risk assessment. Clin Med. 2013;13(6):602-6. https://doi.org/10.7861/ clinmedicine.13-6-602.

22. Dakhil Z, Alsuz I. How can an ideal healthcare system enhance the decision making of heart team in critical situations? J Am Coll Cardiol. 2020;75(11 Supplement 1):3546.

23. France24.com [Internet]. Iraq doctors say vendettas threaten their lives as they save others. Accessed at April 2019. Available at: https://www.france24. com/en/20190228-iraq-doctors-say-vendettas-threaten-lives-they-saveothers. 
24. Fox KA, Clayton TC, Damman P, Pocock SJ, de Winter RJ, Tijssen JG, et al. FIR collaboration. Long-term outcome of a routine versus selective invasive strategy in patients with non-ST-segment elevation acute coronary syndrome: a meta-analysis of individual patient data. J Am Coll Cardiol. 2010;55(22):2435-45. https://doi.org/10.1016/j.jacc.2010.03.007.

25. Barbarawi M, Kheiri B, Zayed Y, Barbarawi O, Chahine A, Haykal T, et al. Meta-analysis of optimal timing of coronary intervention in non-ST-acute coronary syndrome. Catheter Cardiovasc Interv. 2019;95(2):185-93. https:// doi.org/10.1002/ccd.28280

26. Kofoed KF, Kelbæk H, Hansen PR, Torp-Pedersen C, Høfsten D, Kløvgaard L, et al. Early versus standard care invasive examination and treatment of patients with non-ST-segment elevation acute coronary syndrome VERDICT randomized controlled trial. Circulation. 2018;138(24):2741-50. https://doi. org/10.1161/CIRCULATIONAHA.118.037152.

\section{Publisher's Note}

Springer Nature remains neutral with regard to jurisdictional claims in published maps and institutional affiliations.

Ready to submit your research? Choose BMC and benefit from:

- fast, convenient online submission

- thorough peer review by experienced researchers in your field

- rapid publication on acceptance

- support for research data, including large and complex data types

- gold Open Access which fosters wider collaboration and increased citations

- maximum visibility for your research: over $100 \mathrm{M}$ website views per year

At $\mathrm{BMC}$, research is always in progress.

Learn more biomedcentral.com/submissions 